\title{
Effects of trunk lean and foot lift exercises in sitting position on abdominal muscle activity and the contribution rate of transversus abdominis
}

\section{$\operatorname{AUTHOR}(S):$}

Motomura, Yoshiki; Tateuchi, Hiroshige;

Komamura, Tomohito; Yagi, Yuta; Nakao, Sayaka; Ichihashi, Noriaki

\section{CITATION:}

Motomura, Yoshiki ... [et al]. Effects of trunk lean and foot lift exercises in sitting position on abdominal muscle activity and the contribution rate of transversus abdominis. European Journal of Applied Physiology 2021, 121(1): 173-181

\section{ISSUE DATE:}

2021-01

\section{URL:}

http://hdl.handle.net/2433/261777

\section{RIGHT:}

This is a post-peer-review, pre-copyedit version of an article published in European Journal of Applied Physiology. The final authenticated version is available online at: http://dx.doi.org/10.1007/s00421-020-04508-0.; The full-text file will be made open to the public on 30 September 2021 in accordance with publisher's 'Terms and Conditions for SelfArchiving'.; この論文は出版社版でありません。引用の際には出版社版をご確認ご利用ください。; This is not the published version. Please cite only the published version. 
1 Effects of trunk lean and foot lift exercises in sitting position on abdominal muscle activity

2 and the contribution rate of transversus abdominis

3

4 Yoshiki Motomura ${ }^{1}$, Hiroshige Tateuchi ${ }^{1}$, Tomohito Komamura ${ }^{2}$, Yuta Yagi $^{3}$, Sayaka Nakao $^{1}$, Noriaki

$5 \quad$ Ichihashi $^{1}$

6

7 1. Human Health Sciences, Graduate School of Medicine, Kyoto University, Kyoto, Kyoto, Japan

8 2. Division of Rehabilitation Medicine, Chiba University Hospital, Chiba, Chiba, Japan

9 3. Department of Rehabilitation, Rinku General Medical Center, Izumisano, Osaka, Japan

11 Corresponding author

12 Yoshiki Motomura (E-mail: motomura.yoshiki.32z@kyoto-u.jp)

14 ORCID

15 Yoshiki Motomura: 0000-0002-6544-0678

16 Sayaka Nakao: 0000-0001-5714-0336

17 Noriaki Ichihashi: 0000-0003-2508-2172

18

19 


\section{Acknowledgements}

21 The authors gratefully acknowledge all participants involved in this study. This study was not funded by any institutions, agencies, or companies.

\section{Declarations}

25 Funding: Not applicable.

26 Conflicts of interest: Not applicable.

Ethics approval: All the procedures performed in the studies involving human participants were in accordance

Consent: Informed consent was obtained from all individual participants involved in the study. article. 


\section{Abstract}

Purpose: Abdominal hollowing exercise has been recommended to improve trunk stability. Trunk lean and foot

lift exercises while sitting may easily promote abdominal muscle activity even in people who cannot perform abdominal hollowing consciously. The purpose of the present study was to examine the changes in abdominal muscle activity and contribution rate of the transversus abdominis muscle ( $\operatorname{Tr} A)$ when leaning the trunk and lifting the foot during sitting.

Methods: The muscle stiffnesses (indicators of muscle activity) of the right rectus abdominis, external oblique, internal oblique, and $\operatorname{TrA}$ of 14 healthy men were measured during abdominal hollowing and the following nine sitting tasks: reference posture, $15^{\circ}$ and maximal posterior trunk lean, $20^{\circ}$ and maximal ipsilateral and contralateral trunk lean, and ipsilateral and contralateral foot lift. The TrA contribution rate was calculated by dividing the TrA stiffness by the sum of the abdominal muscles' stiffnesses.

Results: The TrA stiffness was significantly higher in abdominal hollowing than in reference posture, posterior and ipsilateral trunk lean, and ipsilateral foot lift, but not higher than in contralateral trunk lean and contralateral foot lift. There was no significant difference in the TrA contribution rates between abdominal hollowing and ipsilateral or contralateral foot lift.

Conclusion: The contralateral trunk lean or contralateral foot lift could enhance TrA activity for people who cannot perform abdominal hollowing consciously. The contralateral foot lift could particularly be beneficial to obtain selective activity of TrA. 


\section{Keywords}

59

abdominal hollowing, muscle stiffness, transversus abdominis, internal oblique, external oblique, rectus abdominis

60

\section{Abbreviations}

$62 \quad \operatorname{Tr} \mathrm{A}$

Transversus abdominis muscle

63

ANOVA

Analysis of variance

64 SWE

Shear wave elastography

65

66 
67

68

69

70

71

72

73

74

75

76

\section{Introduction}

The transversus abdominis muscle (TrA) plays an important role in trunk stabilization while moving the extremities (Hodges and Richardson 1996, 1998; Hodges et al. 1997; Okubo et al. 2013). Since the TrA acts to tighten the abdomen even when the activities of the other abdominal muscles remain unchanged, greater $\operatorname{Tr} A$ activity may allow for a more effective increase in intra-abdominal pressure, which increases the stiffness of the lumbar spine (Hodges et al. 2005). Therefore, improving TrA contribution rate, which is the percentage of $\operatorname{Tr} A$ activity in all the abdominal muscle activities, is required to increase spinal stiffness and reduce spinal loading (Aspden 1988).

Abdominal hollowing exercise, which retracts the abdomen consciously, has been commonly used to train the $\operatorname{TrA}$ (Beith et al. 2001; Koh et al. 2014). Isolated TrA activation using very low-intensity abdominal hollowing may be effective to promote muscle recruitment such as improving the delay in neuromuscular activity of $\operatorname{Tr} A$ (Tsao and Hodges 2007). On the other hand, a previous study found that as the intensity of abdominal hollowing increased, the TrA activity increased significantly and the ratio of the $\operatorname{Tr} A$ to the internal oblique, external oblique, and rectus abdominis did not change (Shimizu et al. 2019). That is, abdominal hollowing at a higher intensity may more effectively improve the function of the TrA that stabilizes the trunk.

Greater decrease in the abdominal cavity during abdominal hollowing reflects stronger contraction of the $\operatorname{Tr} A$ (Richardson et al. 2004). Hides et al. (2008) reported that there was no significant difference in the TrA thickness and abdominal cavity at rest between those with and without low back pain, and the abdominal cavity during abdominal hollowing was significantly larger in those with low back pain than those without. Therefore, patients 
with low back pain may have difficulty exerting voluntary TrA contraction even in the absence of atrophy. Hence, training methods targeting involuntary activation of TrA are important for patients with low back pain.

The prone bridge exercise activates abdominal muscles involuntarily by resisting the gravity from the posture change (Okubo et al. 2010; Shiju Majeed et al. 2019). However, methods promoting abdominal muscle activity through dynamic posture changes, such as prone bridge, have high physical loads and are not necessarily safe for patients with low back pain (Ekstrom et al. 2008; Bhadauria and Gurudut 2017). Though some studies have reported the relation between abdominal muscle activity and sagittal spinal alignment in sitting (O'Sullivan et al. 2002; Astfalck et al. 2010; Claus et al. 2018), these studies did not focus on exercises. However, considering these studies, the TrA activity may be involuntarily increased by leaning the trunk or lifting the foot during sitting, even in patients with low back pain and elderly people with difficulty in changing posture dynamically with high intensity. Foot lift exercises are not changed trunk posture, but may increase abdominal muscle activity to increase lumbar and pelvic stiffness, in order to stabilize the pelvis and to exert hip flexion torque effectively. Revealing how the abdominal muscles activate when leaning the trunk and lifting the foot during sitting may provide knowledge for rehabilitation to stabilize trunks in patients with low back pain and elderly people.

The purpose of this study was to verify the effect of trunk lean and foot lift exercises during sitting on abdominal muscle activity and $\operatorname{TrA}$ contribution rate. The hypothesis was that the activity of all abdominal muscles will be highest in the posterior trunk lean because the spine is more unstable in flexion and extension than in lateral flexion (Yamamoto et al. 1989). It was also hypothesized that $\operatorname{TrA}$ contribution rate would be highest in the contralateral trunk lean where rectus abdominis activity may be more decreased among the abdominal muscles, according to 


\section{Methods}

\section{Participants}

109 A total of 14 healthy men (age, $24.6 \pm 2.9$ years; height, $172.5 \pm 6.1 \mathrm{~cm}$; mass, $66.9 \pm 9.0 \mathrm{~kg}$ ) volunteered for this study. The exclusion criteria were a history of low back pain lasting more than three months(Chou et al. 2007),

111 operation and neurological or orthopedic diseases in the trunk or lower limbs. A power analysis with an $\alpha$ error $=$ 0.05 , power $=0.80$, and effect size $f=0.25$ (medium) was performed by the $\mathrm{G}^{*}$ Power 3.1 analysis software

114 This produced a minimum total sample size of 12 . This study was approved by the ethics committee of Kyoto objectives and the risks involved in the experiment.

To minimize the differences in muscle activity due to different spinal alignments in each participant's natural sitting 
124 lumbar hyperflexion). Participants randomly performed tasks maintaining the following postures (Fig 1. b-f): leaning the trunk posterior to $15^{\circ}$ and maximum from reference posture (posterior trunk lean), leaning the trunk at $20^{\circ}$ and maximum to ipsilateral and contralateral from reference posture (ipsilateral and contralateral trunk lean), and lifting the ipsilateral and contralateral foot about $1 \mathrm{~cm}$ from the floor (ipsilateral and contralateral foot lift). abdominal hollowing while trying to maintain the pressure at $40 \mathrm{mmHg}$. 
preset) of the Aixplorer ultrasound scanner (v6.4; Supersonic Imagine, Aix-en-Provence, France):

$$
\mu(\mathrm{kPa})=\rho V s^{2},
$$

145 where $\rho=$ muscle tissue density $\left(1,000 \mathrm{~kg} / \mathrm{m}^{3}\right)$, and $V s=$ propagation velocity of the shear wave generated by the ultrasonic transducer. An ultrasonic probe (SL15-4 transducer) was in parallel to the fiber orientation of the target the center of each muscle (Fig 2). Reports state that muscle stiffness increases with muscle activity (Bouillard et stiffnesses of all four abdominal muscles.

Another examiner who did not operate the ultrasonic equipment carefully checked visually to ensure no obvious measured twice using the Spinal Mouse (Index Ltd., Tokyo, Japan) before every measurement for muscle stiffness. 
0.73 to 0.88 . The average angles of thoracic kyphosis and lumbar lordosis were calculated from these data. The average angle of pelvic posterior inclination at the height of the second sacrum measured three times using an inclinometer (Wixey, USA) was calculated, and intra-rater reliability $\left(\mathrm{ICC}_{1,1}\right)$ ranged from 0.89 to 0.98 . The average angle of the maximum spine inclination to posterior and right/left measured three times using a goniometer

\section{Statistical analysis}

Statistical analysis was performed using SPSS version 22.0 (SPSS Japan Inc., Tokyo, Japan). The one-way

\section{Results}


181 significant main effects of tasks in one-way repeated measures ANOVA. TrA stiffness was significantly higher in abdominal hollowing than in all other tasks, except for contralateral trunk lean (at $20^{\circ}$ and maximum) and foot lift.

TrA stiffness in the maximum contralateral trunk lean was significantly higher than that in the reference posture, posterior trunk lean (at $15^{\circ}$ and maximum), and ipsilateral foot lift. The stiffness of the internal oblique was significantly higher in abdominal hollowing than in all other tasks, except for contralateral trunk lean (at $20^{\circ}$ and maximum), and was significantly higher in the maximum contralateral trunk lean than in reference posture, posterior trunk lean (at $15^{\circ}$ and maximum), ipsilateral trunk lean (at $20^{\circ}$ and maximum), and ipsilateral foot lift. The stiffness of the external oblique was significantly higher in the posterior trunk (at $15^{\circ}$ and maximum) and contralateral trunk leans (at $20^{\circ}$ and maximum) than in all other tasks, but there were no significant differences among the four tasks of the posterior trunk (at $15^{\circ}$ and maximum) and contralateral trunk leans (at $20^{\circ}$ and maximum). The stiffness of rectus abdominis was significantly higher in the posterior trunk lean at maximum than in all other tasks. in one-way repeated measures ANOVA. The TrA contribution rate in abdominal hollowing was significantly higher than that in the posterior trunk lean (at $15^{\circ}$ and maximum), ipsilateral trunk lean at maximum, and contralateral trunk lean (at $20^{\circ}$ and maximum). There was no significant difference in TrA contribution rate between abdominal hollowing and reference posture, ipsilateral trunk lean at $20^{\circ}$, and ipsilateral and contralateral foot lift. 
higher in the posterior trunk lean than in reference posture. oblique stiffness in the reference posture tended to be low in the ipsilateral foot lift $(r=-0.742, p=0.002)$ and high

\section{Discussion}

The present study was the first, to our knowledge, to investigate noninvasively the effects of trunk lean and foot

lift exercises during sitting on abdominal muscle activity. High TrA activity was exerted in the contralateral trunk

$\operatorname{TrA}$ contribution rate. Therefore, these may be useful in the consideration of targeted $\operatorname{Tr} A$ exercises to stabilize the trunk of elderly people and patients with low back pain. 
extension than in lateral flexion (Yamamoto et al. 1989). The TrA may have an important role holding the trunk and maintaining the posture predictively while other muscles contract (Hodges and Richardson 1997; Allison et al. 2008). On the other hand, previous study showed using wire electromyography that the activity of the $\operatorname{Tr} A$ and internal oblique increased when pulled to contralateral sides, while the activity of the external oblique and rectus abdominis increased when pulled posteriorly (Eriksson Crommert et al. 2017). This study supports our results.

224 Therefore, the present study indicates that all abdominal muscles, even the TrA working to stabilize the trunk, may orientations. Moreover, the neutral zone, which is the range of inter-vertebral motion whereby spinal stiffness (i.e. the force required to make a constant displacement between the vertebrae) is the lowest (Panjabi 1992), has been reported to increase with ligament damage and disc degeneration (Panjabi et al. 1989; Hasegawa et al. 2008).

Busscher et al. (2009) indicated that the lumbar vertebrae had less spinal stiffness in lateral bending in a wider

230 range of motion than the lower thoracic vertebrae and might have less resistance of passive tissue such as ligaments.

231 Therefore, $\operatorname{TrA}$ activity is more likely to increase in lateral trunk lean than posterior trunk lean due to its anatomical

232 function. The present study supports the role of $\operatorname{TrA}$ in increasing spinal stiffness. However, because this study did

233 not verify the load on the spine during the task, further studies should determine whether direction-specific activity

234 of the TrA reflects direction-specific properties of the spine.

235 The TrA contribution rate was significantly higher in the foot lift than in the posterior or the contralateral trunk 
foot lift. The reason why the activity of the rectus abdominis and oblique abdominal muscles, which are the global muscles (Bergmark 1989), did not increase much may be because the trunk load from gravity was lower in foot lift than in contralateral trunk lean. Therefore, the increase in TrA contribution rate in foot lift may be attributed to

241 these circumstances. On the other hand, the low TrA contribution rate during contralateral trunk lean may be due to the requirement to stabilize not only the lumbopelvic region but also the entire spinal alignment against gravity,

243 rendering isolated $\operatorname{TrA}$ activity insufficient. In other words, the rectus abdominis, external oblique and internal

244 oblique muscles may have been activated to stabilize the thorax.

247 other abdominal muscles. Therefore, high $\operatorname{TrA}$ contribution rate (i.e. higher TrA activity when those of other

248 abdominal muscles remain unchanged) may be important in allowing for more effective increase of intra-

249 abdominal pressure, which leads to the increase of spinal stiffness (Hodges et al. 2005; Hides et al. 2006). However,

251 improving disability due to low back pain between the specific training for $\operatorname{Tr} A$ and multifidus muscles and general 
internal oblique, external oblique and rectus abdominis muscles in the reference posture. The results showed that

TrA contribution rate in those with high stiffness of external obliques in the reference posture tended to be low

260 that the particular exercises required to improve TrA contribution rate may differ according to the properties of

261 abdominal muscles during the sitting position. Further study should better understand which subgroups of patients

262 with low back pain require exercise with a high TrA contribution rate (Hill et al. 2008; Macedo et al. 2014). muscle stiffness in this study were similar to those in a previous SWE study (Shimizu et al. 2019), verification of abdominal muscle activities using abdominal muscles' stiffnesses is considered appropriate. Neuromuscular activity measured by a surface or wire electromyography and muscle thickness by an ultrasonic device have been contraction may not necessarily be proportional to increases in abdominal muscle activities (Hodges et al. 2003;

Whittaker et al. 2013). In addition, surface electromyography cannot measure the $\operatorname{Tr} A$, a deep muscle, and wire electromyography is invasive. The SWE in the present study can measure a deep muscle noninvasively and may be useful for verifying abdominal muscle (especially TrA) activity. Since spinal motion greatly influences abdominal muscle activity because of abdominal muscle anatomy, the experiment paid attention to spinal motion. To avoid fatigue due to an increase in the number of tasks measured, 
276 significant differences in thoracic kyphosis, lumbar lordosis, and pelvic inclination angles between tasks; thus,

277 evident spinal motion probably did not occur in this study. The second limitation was that only men participated

278 in the present study. The mobilities of and load on the sacroiliac joint are reported to be greater in women than in

279 men (Joukar et al. 2018); therefore, since lower fibers of the TrA increase the stiffness of the sacroiliac joint, results

280 may differ in a female study population. Third, the tasks used in present study were not exercises whereby TrA

281 was activated in isolation. Lastly, they may not be appropriate for all patients with low back pain.

282

\section{Conclusion}

284 This study investigated noninvasively the effects of trunk lean and foot lift exercises during sitting on abdominal

285 muscle activity. Higher TrA activity was exerted by leaning the trunk to the contralateral side and lifting the

contralateral foot. Furthermore, TrA contribution rate in the contralateral foot lift was similar to that in maximum

abdominal hollowing. As elderly people and patients with low back pain who have difficulty in consciously 


\section{Compliance with Ethical Standards}

\section{Disclosure of potential conflicts of interest}

292 Conflict of Interest: The authors declare that they have no conflict of interest.

293

294 Research involving Human Participants and/or Animals

295 Ethics approval: All the procedures performed in the studies involving human participants were in accordance with

and its later amendments or comparable ethical standards. This study was approved by the ethics committee of

Kyoto University Graduate School and the Faculty of Medicine (R0546-2)

299

300

\section{Informed consent}

301 Informed consent was obtained from all individual participants involved in the study. 


\section{$303 \quad$ References}

304 Allison GT, Morris SL, Lay B (2008) Feedforward Responses of Transversus Abdominis Are Directionally workplace. $319-323$. with and without nonspecific chronic low back pain: an analysis based on subclassification. Spine (Phila

Bergmark A (1989) Stability of the lumbar spine: A study in mechanical engineering. Acta Orthop 60:1-54. doi:

Bhadauria EA, Gurudut P (2017) Comparative effectiveness of lumbar stabilization, dynamic strengthening, and 
322

324

Busscher I, Van Dieën JH, Kingma I, et al (2009) Biomechanical characteristics of different regions of the human spine: An in vitro study on multilevel spinal segments. Spine (Phila Pa 1976) 34:2858-2864. doi: 10.1097/BRS.0b013e3181b4c75d

Chou R, Snow V, Casey D, et al (2007) Clinical Guidelines Diagnosis and Treatment of Low Back Pain : A Joint Clinical Practice Guideline from the American College of Physicians and the American. Ann Intern Med 147:478-491.

Claus AP, Hides JA, Moseley GL, Hodges PW (2018) Different ways to balance the spine in sitting: Muscle activity in specific postures differs between individuals with and without a history of back pain in sitting. Clin Biomech 52:25-32. doi: 10.1016/j.clinbiomech.2018.01.003

Ekstrom RA, Osborn RW, Hauer PL (2008) Surface Electromyographic Analysis of the Low Back Muscles During Rehabilitation Exercises. J Orthop Sport Phys Ther 38:736-745. doi: 10.2519/jospt.2008.2865

Eriksson Crommert M, Tucker K, Holford C, et al (2017) Directional preference of activation of abdominal and paraspinal muscles during position-control tasks in sitting. J Electromyogr Kinesiol 35:9-16. doi: 10.1016/j.jelekin.2017.05.002

Hasegawa K, Kitahara K, Hara T, et al (2008) Evaluation of lumbar segmental instability in degenerative diseases by using a new intraoperative measurement system. J Neurosurg Spine 8:255-262. doi: $10.3171 /$ spi/2008/8/3/255

Hides J, Stanton W, Freke M, et al (2008) MRI study of the size, symmetry and function of the trunk muscles among elite cricketers with and without low back pain. Br J Sports Med 42:509-513. doi: 
Hides J, Wilson S, Stanton W, et al (2006) An MRI investigation into the function of the transversus abdominis

Hill JC, Dunn KM, Lewis M, et al (2008) A primary care back pain screening tool: Identifying patient subgroups for initial treatment. Arthritis Care Res 59:632-641. doi: 10.1002/art.23563

Hodges PW, Eriksson AEM, Shirley D, Gandevia SC (2005) Intra-abdominal pressure increases stiffness of the lumbar spine. 38:1873-1880. doi: 10.1016/j.jbiomech.2004.08.016

Hodges PW, Gandevia SC, Richardson CA (1997) Contractions of specific abdominal muscles in postural tasks are affected by respiratory maneuvers. J Appl Physiol 83:753-760.

Hodges PW, Pengel LHM, Herbert RD, Gandevia SC (2003) Measurement of muscle contraction with ultrasound imaging. Muscle and Nerve 27:682-692. doi: 10.1002/mus.10375

Hodges PW, Richardson CA (1996) Inefficient muscular stabilization of the lumbar spine associated with low back pain. A motor control evaluation of transversus abdominis. Spine (Phila. Pa. 1976). 21:2640-50.

Hodges PW, Richardson CA (1997) Contraction of the abdominal muscles associated with movement of the lower limb. Phys Ther 77:132-142; discussion 142-144.

Hodges PW, Richardson CA (1998) Delayed postural contraction of transversus abdominis in low back pain 
Kiesel KB, Underwood FB, Mattacola CG, et al (2007) A Comparison of Select Trunk Muscle Thickness and Asymptomatic Controls. J Orthop Sport Phys Ther 37:596-607. doi: 10.2519/jospt.2007.2574 sectional Areas of Abdominal Muscles in Middle-aged Women. J Phys Ther Sci 26:295-299. doi:

MacDonald D, Wan A, McPhee M, et al (2016) Reliability of Abdominal Muscle Stiffness Measured Using

Macedo LG, Maher CG, Hancock MJ, et al (2014) Predicting Response to Motor Control Exercises and Graded perturbations in sitting. Clin Biomech 24:176-182. doi: 10.1016/j.clinbiomech.2008.12.001 on Trunk Muscle Activity in a Pain-Free Population. Spine (Phila Pa 1976) 27:1238-1244. doi: 
Okubo Y, Kaneoka K, Shiina I, et al (2013) Abdominal Muscle Activity During a Standing Long Jump. J Orthop

Panjabi M, Abumi K, Duranceau J, Oxland T (1989) Spinal stability and intersegmental muscle forces. A

Richardson CA, Hides JA, Wilson S, et al (2004) Lumbo-pelvic joint protection against antigravity forces: motor control and segmental stiffness assessed with magnetic resonance imaging. J Gravit Physiol 11:119-122.

Saragiotto BT, Maher ÃCG, Tie Ã (2016) Motor Control Exercise for Nonspecific Low Back Pain. Spine (Phila Pa 1976) 41:1284-1295. doi: 10.1002/14651858.CD012004. program (TRICCS-Trivandrum Community-based Core Stabilisation) for community-based intervention abdominal hollowing: Selecting the optimal training intensity for the transversus abdominis muscle. J 
398

399

400

401

402

403

404

405

406

407

408

409

410

411

412

associated with radiographic progression of secondary hip osteoarthritis. Osteoarthr Cartil 26:397-404.

doi: 10.1016/j.joca.2017.12.005

Tesh KM, Dunn JS, Evans JH (1987) The abdominal muscles and vertebral stability. Spine (Phila Pa 1976)

12:501-508.

Tsao H, Hodges PW (2007) Immediate changes in feedforward postural adjustments following voluntary motor training. Exp Brain Res 181:537-546. doi: 10.1007/s00221-007-0950-z

Whittaker JL, McLean L, Hodder J, et al (2013) Association Between Changes in Electromyographic Signal Amplitude and Abdominal Muscle Thickness in Individuals With and Without Lumbopelvic Pain. J Orthop Sport Phys Ther 43:466-477. doi: 10.2519/jospt.2013.4440

Yamamoto I, Panjabi MM, Crisco T, Oxland T (1989) Three-dimensional movements of the whole lumbar spine and lumbosacral joint. Spine (Phila Pa 1976) 14:1256-60. doi: 10.1097/00007632-198911000-00020

(1) 

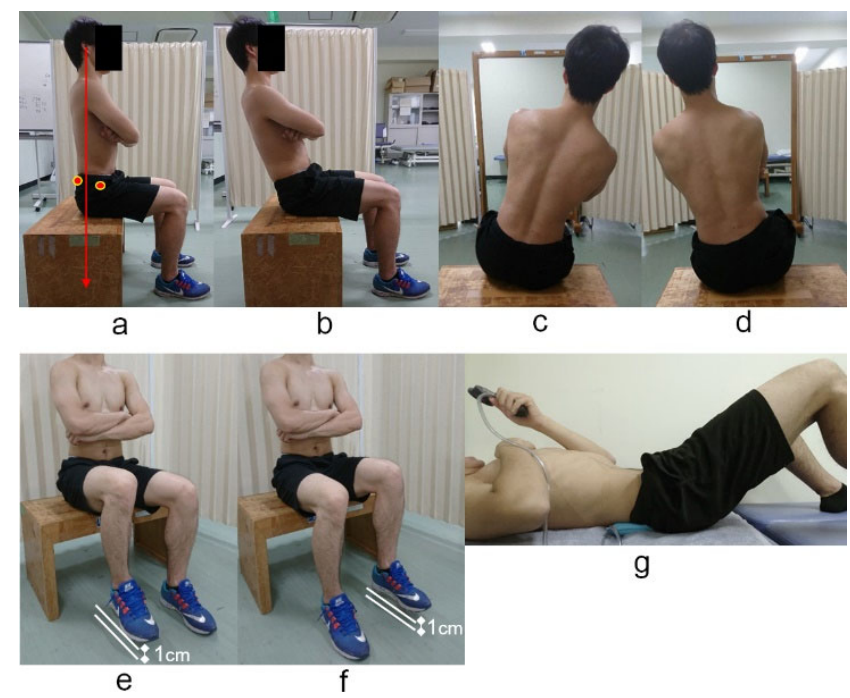

414 Fig. 1 Task postures. a reference posture; b posterior trunk lean; c ipsilateral trunk lean; $d$ contralateral trunk lean;

e ipsilateral foot lift; $f$ contralateral foot lift; $g$ abdominal hollowing with maximal effort. The reference posture

was defined as a natural posture for each participant where the perpendicular line from ear hole to the floor was

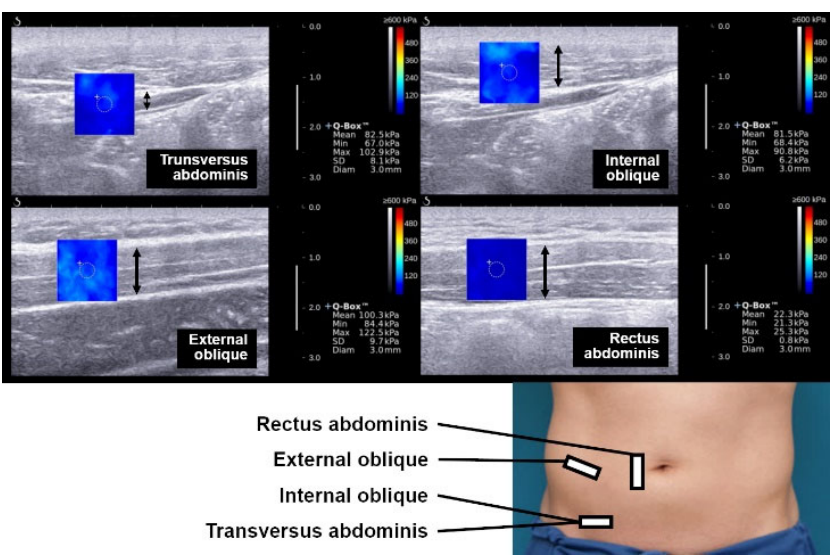

Fig. 2 Representative images and measurement sites of the stiffness of abdominal muscles 
424 Table 1 The stiffnesses of abdominal muscles and the contribution rate of transversus abdominis during tasks

\begin{tabular}{|c|c|c|c|c|c|}
\hline & $\begin{array}{l}\text { Transversus } \\
\text { abdominis } \\
{[\mathrm{kPa}]}\end{array}$ & $\begin{array}{l}\text { Internal } \\
\text { oblique } \\
{[\mathrm{kPa}]}\end{array}$ & $\begin{array}{l}\text { External } \\
\text { oblique } \\
{[\mathrm{kPa}]}\end{array}$ & $\begin{array}{l}\text { Rectus } \\
\text { abdominis } \\
{[\mathrm{kPa}]}\end{array}$ & $\begin{array}{l}\text { Contribution } \\
\text { rate of } \\
\text { transversus } \\
\text { abdominis } \\
{[\%]}\end{array}$ \\
\hline & $2,3,4,5,6,9$ & $2,3,4,5,6,9,10$ & & 2 & $3,4,6,7,8$ \\
\hline $\begin{array}{l}\text { Abdominal hollowing } \\
\text { with maximal effort (1) }\end{array}$ & $39.5 \pm 18.0$ & $48.2 \pm 20.9$ & $12.4 \pm 9.3$ & $18.2 \pm 8.9$ & $33.8 \pm 7.5$ \\
\hline Reference posture & $11.3 \pm 4.7$ & $13.8 \pm 7.9$ & $6.8 \pm 4.3$ & $7.9 \pm 3.2$ & $28.7 \pm 8.4$ \\
\hline $\begin{array}{l}\text { Posterior trunk lean } \\
\qquad \text { at } 15^{\circ}(3)\end{array}$ & $12.3 \pm 10.7$ & $11.3 \pm 10.1$ & $\begin{array}{r}1,2,5,6,9,10 \\
36.3 \pm 14.1\end{array}$ & $36.1 \pm 19.0$ & $12.0 \pm 7.7$ \\
\hline $\begin{array}{l}\text { Posterior trunk lean } \\
\qquad \text { at } \max (4)\end{array}$ & $9.3 \pm 4.3$ & $10.7 \pm 4.8$ & $\begin{array}{r}1,2,5,6,9,10 \\
66.4 \pm 21.1\end{array}$ & $\begin{aligned} & 1,2,3,5,6,7,8,9,10 \\
& 70.6 \pm 22.0\end{aligned}$ & $6.1 \pm 2.8$ \\
\hline $\begin{array}{l}\text { Ipsilateral trunk lean } \\
\qquad \text { at } 20^{\circ}(5)\end{array}$ & $13.3 \pm 6.4$ & $14.3 \pm 6.0$ & $8.0 \pm 4.9$ & $18.0 \pm 17.7$ & $25.9 \pm 8.9$ \\
\hline $\begin{array}{l}\text { Ipsilateral trunk lean } \\
\text { at } \max (6)\end{array}$ & $18.8 \pm 9.4$ & $20.5 \pm 10.1$ & $12.8 \pm 6.9$ & $20.1 \pm 10.2$ & $25.8 \pm 7.0$ \\
\hline $\begin{array}{l}\text { Contralateral trunk lean } \\
\qquad \text { at } 20^{\circ}(7)\end{array}$ & $19.6 \pm 8.1$ & $26.5 \pm 10.6$ & $\begin{array}{r}1,2,5,6,9,10 \\
42.1 \pm 10.3\end{array}$ & $13.7 \pm 6.2$ & $19.5 \pm 7.7$ \\
\hline $\begin{array}{l}\text { Contralateral trunk lean } \\
\qquad \text { at } \max (8)\end{array}$ & $26.1 \pm 11.5^{2,3,4,9}$ & $\begin{array}{r}2,3,4,5,6,9 \\
36.1 \pm 15.3\end{array}$ & $\begin{array}{r}1,2,5,6,9,10 \\
55.4 \pm 19.0\end{array}$ & $27.7 \pm 18.4$ & $18.3 \pm 7.0$ \\
\hline Ipsilateral foot lift & $14.0 \pm 4.6$ & $15.4 \pm 6.4$ & $9.6 \pm 7.0$ & $9.2 \pm 5.7$ & $29.3 \pm 7.7^{3,4,8}$ \\
\hline Contralateral foot lift & $18.0 \pm 7.8$ & $20.7 \pm 7.7$ & $7.1 \pm 7.1$ & $13.6 \pm 11.4$ & $31.2 \pm 8.8^{3,4,7,8}$ \\
\hline
\end{tabular}

425 Values are expressed as mean \pm standard deviation 
Table 2 Spinal alignment during each task

\begin{tabular}{|c|c|c|c|c|}
\hline & $\begin{array}{l}\text { Thoracic } \\
\text { kyphosis }\left[^{\circ}\right] \\
(\mathrm{n}=12)\end{array}$ & $\begin{array}{l}\text { Lumbar } \\
\text { lordosis }\left[^{\circ}\right] \\
(\mathrm{n}=12)\end{array}$ & $\begin{array}{l}\text { Pelvic } \\
\text { inclination }\left[^{\circ}\right] \\
(n=14)\end{array}$ & $\begin{array}{l}\text { Spinal } \\
\text { inclination }\left[^{\circ}\right] \\
(\mathrm{n}=14)\end{array}$ \\
\hline Reference posture & $29.1 \pm 6.0$ & $2.8 \pm 7.3$ & $1.0 \pm 9.1$ & \\
\hline $\begin{array}{l}\text { Posterior trunk lean } \\
\qquad \text { at } 15^{\circ}\end{array}$ & $31.0 \pm 6.1$ & $4.0 \pm 9.6$ & $11.9 \pm 8.8 *$ & \\
\hline $\begin{array}{l}\text { Posterior trunk lean } \\
\text { at max }\end{array}$ & $32.0 \pm 6.4$ & $5.8 \pm 8.0$ & $24.8 \pm 11.5 *$ & $28.7 \pm 5.2$ \\
\hline $\begin{array}{l}\text { Ipsilateral trunk lean } \\
\text { at } 20^{\circ}\end{array}$ & $34.0 \pm 8.2$ & $10.9 \pm 10.8$ & $-1.5 \pm 9.6$ & \\
\hline $\begin{array}{l}\text { Ipsilateral trunk lean } \\
\text { at max }\end{array}$ & $29.6 \pm 6.8$ & $8.2 \pm 6.4$ & $-1.8 \pm 8.9$ & $28.5 \pm 3.8$ \\
\hline $\begin{array}{r}\text { Contralateral trunk lean } \\
\text { at } 20^{\circ}\end{array}$ & $31.2 \pm 6.4$ & $8.7 \pm 7.6$ & $-1.4 \pm 9.5$ & \\
\hline $\begin{array}{r}\text { Contralateral trunk lean } \\
\text { at max }\end{array}$ & $31.1 \pm 6.8$ & $6.8 \pm 6.9$ & $-4.2 \pm 8.7$ & $29.4 \pm 4.6$ \\
\hline Ipsilateral foot lift & $28.2 \pm 5.9$ & $7.9 \pm 8.4$ & $1.7 \pm 10.1$ & \\
\hline Contralateral foot lift & $26.8 \pm 6.0$ & $7.1 \pm 6.5$ & $0.2 \pm 9.9$ & \\
\hline
\end{tabular}

429 The positive values in pelvic inclination represent the sacral posterior inclination angle on the sagittal plane 